Door: Bert ter Mors (b.ter.mors@ggzoostbrabant.nl), neuropsychiater, Academisch Centrum voor Epileptologie Kempenhaeghe/Maastricht UMC+, Heeze en Hoogspecialistisch Centrum voor Hersenletsel en Neuropsychiatrie, GGZ Oost Brabant, Huize Padua, Boekel en Mebeline Boon, neuropsychiater, Hoogspecialistisch Centrum voor Hersenletsel en Neuropsychiatrie, GGZ Oost Brabant, Huize Padua, Boekel

\title{
Neuropsychiatrische problemen na epilepsiechirurgie
}

Aan de hand van een casus worden persoonlijkheids- en gedragsverandering na epilepsiechirurgie besproken. Verschillende syndromen worden beschreven in relatie tot de operatielocatie. $(\mathrm{H})$ erkenning van deze veranderingen na epilepsiechirurgie gedurende het hele traject wordt aanbevolen en betrokkenheid van een neuropsychiater met ervaring met de gevolgen van hersenletsel wordt voorgesteld.

Epilepsiechirurgie is de afgelopen decennia volop in ontwikkeling en krijgt een steeds prominentere plek in de behandeling van therapieresistente epilepsie (Schijns et al., 2015). Het ontwikkelen van een psychiatrische stoornis na epilepsiechirurgie is één van de complicaties: $7 \%$ van de patiënten heeft na epilepsiechirurgie een de novo psychiatrische stoornis ontwikkeld (van Veelen et al. 200I). In de meeste gevallen gaat het dan om een depressieve stoornis (Van Veelen et al., 200I). Een psychose is bij $2 \%$ een zeldzamere maar ernstige complicatie (Vivekananda et al., 20r6).
Echter, naast psychiatrische stoornissen in engere zin, vallen ook gedragsstoornissen en persoonlijkheidsverandering, vaak in combinatie met cognitieve problemen, onder de mogelijke neuropsychiatrische gevolgen van hersenletsel door hersenchirurgie. Deze worden niet beschreven in de richtlijn Epilepsie, maar wel in de 'Richtlijn: Diagnostiek en Behandeling van Neuropsychiatrische gevolgen van Hersenletsel' (https://richtlijnendatabase.nl/richtlijn/ neuropsychiatrische_gevolgen_na_nah_bij volwassenen). Er zijn slechts enkele studies bekend die de mogelijkheid van persoonlijkheidsverandering indiceren, waarbij het

De drie klinisch herkenbare frontale syndromen zijn:

I Het dorsolateraal prefrontaal syndroom (dysexecutief syndroom), dat gekenmerkt wordt door:

- beperkte verbale fluency

- beperkt abstractie vermogen

- oordeels- en kritiekstoornissen

- geheugenproblemen parallel aan planningsproblemen

- executieve stoornissen, geen overzicht in complexe situaties.

- onmogelijkheid om een motorische activiteit vol te houden

- utilisatiegedrag (automatisch gaan gebruiken van een object in de directe omgeving)

- omgevingsafhankelijkheid voor het komen tot activiteit

- geen mentale flexibiliteit

- aandachtstoornissen

2 Het orbitofrontaal syndroom, dat gekenmerkt wordt door:

- disinhibitie (wegvallen van 'Limbic Police')

- impulsiviteit

- tactloosheid
- stemmingswisselingen

- affect labiliteit of juist vlak affect

- chagrijnigheid

- ongepaste grappen

- decorumverlies

- gebrek aan empathisch vermogen

- egocentriciteit

- interesseverlies

- oordeels- en kritiekstoornissen (wegvallen van 'Limbic Police')

- gewetenloosheid (wegvallen van 'Limbic Police')

2 En het mediofrontaal (anterior cynguli) syndroom, dat gekenmerkt wordt door:

- apathie

- ontbreken van doelgericht gedrag

- ontbreken van doelgericht denken

- emotionele onverschilligheid en vlak affect

- abulie

- mutisme

- gebrek aan initiatief

- psychomotore inertie 
kan gaan om een verlaagde interpersoonlijke sensitiviteit, verlaagde irritatie en verlaagde sociale introversie (Meldolesi et al., 2007) of een toename van angst, emotionele labiliteit en gevoeligheid voor stress (Seropian et al., 20I7). In het Hoogspecialistisch Centrum voor Hersenletsel en Neuropsychiatrie Huize Padua worden regelmatig patiënten behandeld bij wie na epilepsiechirurgie persoonlijkheidsverandering heeft plaatsgevonden. Dit heeft dan grote gevolgen voor het leven van de patiënt en zijn of haar naasten. De impact wordt versterkt door het feit dat het vaak onvoldoende wordt (h)erkend binnen de reguliere zorg. In deze bijdrage worden twee klinische verschijningsvormen beschreven waarvan één geïllustreerd door middel van een casusbeschrijving.

\section{Klinische verschijningsvormen}

Allereerst kunnen na frontaal letsel persoonlijkheids- en gedragsveranderingen optreden. Bij epilepsiechirurgie bij een frontaal focus is dit van toepassing maar ook kunnen door epilepsiechirurgie elders circuits worden onderbroken zodat een frontaal syndroom ontstaat. Cummings \& Trimble (2002) classificeren drie klinisch herkenbare frontale syndromen, die zich door de uitgebreidheid van de resectie kunnen presenteren in gemengde vorm en zich zelden als puur syndroom voordoen. Deze syndromen en de kenmerken die daarbij horen zijn vermeld in het kader, dat op de vorige pagina is weergegeven.

Naast deze frontale beelden kunnen als gevolg van rechts hemisferisch letsel in 50 tot $78 \%$ van de gevallen cognitievecommunicatieproblemen optreden (ter Mors et al., 20I8). Qua interventies wordt er gepleit voor 'context-sensitieve' interventies. Dat houdt in een combinatie van skills-training en training tijdens participatie. Ook werd er een positief effect vastgesteld van psycho-educatie voor communicatie partners (Togher et al., 2013). De impact hiervan wordt hier geïllustreerd door middel van een casusbeschrijving.

\section{Casusbeschrijving}

Het gaat om een 65 -jarige vrouw die sinds 22 jaar bekend is met therapieresistente, lokalisatiegebonden epilepsie, zich uitend in complex partiële aanvallen. Rond 2013 vond er een maximale temporale resectie met amygdalohippocampectomie rechts plaats. Er is dus sprake van rechts hemisferisch letsel (RHL). De uitkomst van een pre- en postoperatief intelligentieonderzoek is weergegeven in tabel I.
Bij een herhalingsonderzoek in 2017 dat werd uitgevoerd op verzoek van patiënte omdat ze vond dat er achteruitgang was, werd ten opzichte van het postoperatieve intelligentieonderzoek van 20I4 geen achteruitgang geconstateerd. Observaties tijdens dit NPO: een starre gezichtsuitdrukking valt op. Ze is breedsprakig en niet te onderbreken. Ze pikt non-verbale signalen van de proefleider niet op. Ze onderbreekt de proefleider als deze instructies geeft waardoor deze niet worden opgepikt. Ze praat zacht en binnensmonds. Ze interpreteert instructies op haar eigen manier, ze vraagt door op irrelevante details of trekt verkeerde conclusies. Waardoor, al met al, instructies verkeerd worden begrepen.

Op de postoperatieve MRI is er in het operatiegebied veel littekenweefsel te zien. Na de operatie vermindert de aanvalsfrequentie bij continueren van de anti-epileptica. Naast de cognitieve veranderingen (zie tabel I) en de quadrantanopsie worden door de neuroloog geen andere veranderingen vastgesteld. Er zijn toenemende problemen in de relatie, die in eerste instantie worden geduid als een exponent van de reeds bestaande relatieproblemen, het echtpaar wordt verwezen naar een relatietherapie in de eerste lijn.

Om een stemmingsstoornis uit te sluiten wordt de patiënte verwezen voor psychiatrisch onderzoek. Anamnestisch vindt ze zichzelf te wijdlopig en ze constateert dat mensen haar links laten liggen. Heteroanamnestisch merkt echtgenoot op dat ze in woordenwisselingen blijft hangen in tegenstelling tot voor de operatie. Ze heeft een kort lontje en ze praat zeer gedetailleerd, zodat hij de draad van haar verhaal kwijtraakt. Voor de operatie was ze stiller, hield zich meer op de achtergrond. Na de operatie is ze kribbig, ze maakt zich snel druk over zaken, is niet verdraagzaam en wordt als eigenwijs ervaren. Ze is breedsprakig, associatief, weidt uit en is moeilijk te onderbreken. Ze heeft moeite met onthouden van gezichten en is sneller emotioneel. Ze heeft een starre mimiek. De neuropsychiater stelt geen stemmingsstoornis vast, maar wel zijn er in dit contact duidelijke aanwijzingen voor cognitieve communicatieproblemen. Daarnaast wordt uit de anamnese en de observaties aannemelijk dat er sprake is van een persoonlijkheidsverandering na de hersenoperatie. Er is sprake van egocentriciteit en een onvermogen tot empathie. Ook is er sprake van anosognosie (geen ziektebesef) waarbij

\begin{tabular}{|l|l|l|l|l|l|}
\hline & TIQ & VIQ & PIQ & Verbaal geheugen & Visueel geheugen \\
\hline Preoperatief 20I2 & 97 & I02 & 92 & I29 & I20 \\
\hline Postoperatief 20I4 & 87 & 98 & 75 & I20 & 96 \\
\hline
\end{tabular}

Tabel 1 Het resultaat van pre-en postoperatief intelligentie onderzoek WAIS III 
ze de oorzaak van de problemen die zij ervaart buiten zichzelf legt, wat vaker voorkomt na een RHL.

\section{Beleid en verloop}

Zowel patiënte als echtgenoot hebben apart van elkaar uitleg gekregen over de stoornissen en advies hoe met de problemen om te gaan. Patiënte kon daar zoals verwacht weinig mee. Ze won wel aan inzicht en kon ook desgevraagd uitleg geven over haar eigen communicatieve beperkingen, maar ze kon tijdens gesprekken daar niet dusdanig rekening mee houden dat deze beter verliepen. Echtgenoot werd bevestigd in zijn visie op de problemen, namelijk dat deze verschijnselen postoperatief zijn ontstaan. Er waren voordien ook relatieproblemen, maar deze waren van geheel andere aard en orde. De communicatie bleef moeizaam en het affectieve aspect van de relatie bleef geheel ontbreken. Een status quo werd bereikt waarbij het echtpaar bij elkaar bleef en gebruik makend van de adviezen een manier vond om de problemen hanteerbaar te maken en houden.

\section{Bespreking}

Hoewel in de literatuur weinig beschreven wordt over persoonlijkheids- en gedragsverandering na epilepsiechirurgie komt dit in de neuropsychiatrische praktijk vaak voor. Overigens kunnen ook al voor de operatie bestaande problemen in persoonlijkheid en gedrag versterkt worden. De epilepsie-populatie is in die zin extra kwetsbaar (Kansu et al., 2017). Door de oorzaak van de epilepsie kunnen al gedragsveranderingen en cognitieve veranderingen opgetreden zijn. Door de epileptische aanvallen kan cumulatieve schade optreden, door een status epilepticus kan blijvende schade optreden en door jarenlang medicatiegebruik kunnen veranderingen optreden. $\mathrm{Al}$ deze verschijnselen kunnen na operatie versterkt naar voren komen. De cognitieve- en persoonlijkheidsveranderingen die een grote impact hebben, worden in een spreekkamer consult niet altijd manifest, zeker als de betreffende behandelaar geen ervaring heeft met het signaleren van deze 'onzichtbare' gevolgen van hersenchirurgie. Als deze problemen niet onderkend worden, zoals voor de hier besproken patiënte, is er het risico dat een verkeerde behandeling of begeleiding wordt gekozen met mogelijk escalatie van de problematiek tot gevolg.

\section{Aanbevelingen voor de klinische praktijk}

Neem elke (hetero)anamnestische signalering van persoonlijkheids- en gedragsverandering na epilepsiechirurgie serieus. Ga ervan uit dat deze gemelde veranderingen mogelijk te maken kunnen hebben met de operatie. Vanuit onze klinische ervaring pleiten we ervoor om de mogelijkheid dat persoonlijkheids- en gedragsverandering kan optreden mee te nemen in het informed consent proces voor operatie en ook om zo mogelijk aan de hand van de locatie van de operatie te voorspellen welke veranderingen verwacht kunnen worden. Bij voor de operatie al bestaande problemen is het goed om te anticiperen op de problemen die kunnen ontstaan, zowel preoperatief als postoperatief, met daarbij behorende maatregelen die het hanteren van deze veranderingen mogelijk maken. Het betrekken van een neuropsychiater met ervaring met hersenletsel in de procedure zowel preoperatief als postoperatief en in het multidisciplinaire team, dient te worden overwogen (Vivekananda et al., 2015). Verder is meer onderzoek naar het voorkomen van persoonlijkheidsverandering en gedragsverandering na epilepsiechirurgie aan te bevelen.

\section{Referenties}

Cummings JL \& Trimble MR (2002) Concise Guide to Neuropsychiatry and Behavioral Neurology $\left(2^{\text {nd }}\right.$ ed.) Washington DC; American Psychiatry Publishing, ISBN 0-88048-493-4.

Kansu B, Pickrel WO, Hamandi K (2017) The psychiatric risks of temporal epilepsy surgery. What should patients be told? Epilepsy and behavior. 78:315.

Meldolesia GN, Di Gennaroa G, Quaratoa PP, Espositoa,V, Grammaldoa LG, Morosinib P, Cascavilla I, Picardi A (2007) Changes in depression, anxiety, anger, and personality after resective surgery for drug-resistant temporal lobe epilepsy: a 2-year follow-up study. Epilepsy Research 77, 22-30.

Schijns OEMG, Hoogland G, Kubben PL, Koehler PJ (20I5). The start and development of epilepsy surgery in Europe: a historical review. Neurosurg Rev, 38(3):447-461.

Seropian BH, Boucher O, Sénéchal C, Rouleau I, Bouthillier A, Lepore F, Nguyen DK. (2017) Does unilateral insular resection disturb personality? A study with epileptic patients. Case Reports / Journal of Clinical Neuroscience 43; 121-125. Ter Mors AJW, Bus BAA, Reijbroek M (2018) Cognitieve communicatiestoornis ten gevolge van niet-aangeboren hersenletsel in de rechter hemisfeer. Tijdschrift voor Psychiatrie 12, 838-842.

Togher L, McDonald S, Tate R, Power E, Rietdijk R (2013) Training communication partners of people with severe traumatic brain injury improves everyday conversations: a multicenter single blind clinical trial. J Rehabil Med 45: 637-45.

Van Veelen, van Rijen PC, Debets RM, van Wijk-Leenaars PW, van Emde Boas W (200I) Dutch Collaborative Epilepsy Surgery Program: reduction of seizures, operative complications and tapering of medication in 338 patients, I973-I998. Ned Tijdschr voor Geneesk 17;145(46):2223-8. Vivekananda U, Cock H et al. (20I6) Seizure. A case of de novo psychosis ten years following successful epilepsy surgery. European Journal of Epilepsy, 41: 4- 5 . 